$\underline{\text { articles }}$

\title{
The Influence of Background Sounds, Physical Sounds, and Managers' Proactive Customer Service Regarding Situational Sounds on Customer Satisfaction in the Restaurant Industry
}

\author{
Tak M Yeung, MS ${ }^{1}{ }^{a}$, Shiang-Lih Chen McCain, Ph.D. ${ }^{2}$ b , Jeffrey C. Lolli, Ed.D. ${ }^{\text {c }}$, Brian Larson, Ph.D. ${ }^{1}$ d \\ 1 Widener University, ${ }^{2}$ Colorado Mesa University \\ Keywords: Background Sounds, Physical Sounds, Situational Sounds, Ambient Noise, Proactive Customer Service, Customer Satisfaction, Restaurant \\ Industry \\ https://doi.org/10.53703/001c.29831
}

\section{Journal of Small Business Strategy}

Vol. 31, Issue 5, 2021

\begin{abstract}
Noise complaints in restaurants have been accelerating and unpleasant sounds erode customer satisfaction. Restaurant ambient noise, such as background and physical sounds influence customer satisfaction and effectively controlling the sound environment in restaurants is challenging, particularly situational sounds generated by customers. Situational sounds address how customers are influenced by other customers dining in the same restaurant and highlight a type of sound that cannot be easily managed by employees. Situational sounds can be loud conversation among fellow customers or misbehaving children. Concerns with situational sounds are less about how they impact customer satisfaction, and more about the way in which managers handle them. Thus, managers find a proactive service approach to be most effective when handling situational sounds in a restaurant. For example, strategically placing a large noisy group in a separate room or further away from other customers in the restaurant can mitigate the negative impact to other diners. The results of this study confirmed that background sounds, physical sounds, and managers' proactive customer service regarding situational sounds impact customer satisfaction. However, the interactive effects of background sounds, physical sounds, and managers' proactive customer service regarding situational sounds do not influence customer satisfaction. Based on the results, recommendations for restaurant managers are provided to decrease controllable unpleasant noises caused by background and physical sounds as well as strategies for effectively executing proactive customer service to handle situational sounds.
\end{abstract}

\section{Introduction}

Delivering a positive service experience is vital in the hyper-competitive restaurant industry. However, today's restaurants are getting noisier (Spence, 2014) and controlling ambient noise levels is increasingly being recognized for its contribution to the overall customer experience. Soundscape, a sound or combination of sounds from an environment, is so influential that some restaurant-goers have begun calling for legislation to regulate noise levels and restaurant reviews in the Washington Post now come with decibel ratings and explanations (e.g. "Must speak with raised voice") according to Wells (2020).

Ambient noise refers to background sounds, physical sounds, and situational sounds in a restaurant setting
(Hodgson et al., 2007). Background sounds refer to noise from musical compositions, projected radio programming, and other music that can be controlled by restaurant managers (Schafer, 1994). Physical sounds refer to the noise generated by employees, such as placing dishes and silverware onto trays, running around, moving tables and chairs, and cleaning and setting up tables (Zemke et al., 2011). Situational sounds refer to the noise generated by customers, which are part of the product (Bitner, 1990), and which managers do not have full control over (Christie, 2004).

Unpleasant sounds in restaurant settings erode customer satisfaction and noise complaints in restaurants have been accelerating (Hsu, 2012). They are repeatedly the top complaint in Zagat's America's Top Restaurants Survey (Clark, 2014; Morgan, 2016) and to audiologists (National Institute

\footnotetext{
a One University Place, Chester, PA 19013, USA, tmyterry@gmail.com

b 1100 North Ave, Grand Junction, CO 81501, USA, schenmccain@coloradomesa.edu

c One University Place, Chester, PA 19013, USA, jclolli@widener.edu

d One University Place, Chester, PA 19013, USA, bvlarson@widener.edu
} 
on Deafness and Other Communication Disorders, 2016). A 2016 Consumer Reports survey found that excessive noise is the top reason people complain about restaurants - ahead of service or even food quality (Belluz, 2018). Few factors are more central for restaurant managers than managing noise in the restaurant setting.

Established scientific studies show that unpleasant sounds (e.g. background music, the clatter of silverware and dishes, and the conversations from the diners themselves) influence customer satisfaction (Bramley, 2019; Kivela et al., 1999). Not surprisingly, and indicative of its centrality to a good service experience, the concept of soundscape has been commonly applied when investigating noise level.

However, smartly controlling the sound environment in restaurants is challenging. While customer satisfaction partially reflects the impact of the restaurant's sound environment - referred to as ambient conditions (Turley \& Milliman, 2000), the sound environment also results from interactions with the customer themselves. For instance, situational sounds cannot be fully controlled by managers because they are generated by customers who dine in the same setting at the same time. Based on two of the authors' 15 years of restaurant experience, many restaurant managers indicate that the most common practice for them to handle noisy customers is to apply a proactive service approach where managers move customers further away from the noise. This approach avoids making a scene and prevents other customers from being interrupted by their noisy co-diners. The human variables, and management's handling of the human variables, should also affect the service provider's setting.

Often, managers have not been trained to think about service quality holistically and preventatively, but rather reactively. While employees are trained to deliver superior service, often systems are not in place to deal with service problems before they occur. For example, if a large group of diners is too loud and this upsets the guest at the table nearby, the manager may perform a service recovery for the disgruntled guest. However, if the manager initially took a proactive approach, the large group could have been seated away from other diners to avoid upsetting other customers. Proactive customer service plays an essential role because not every dissatisfied customer complains, and many times managers are not even aware of a service failure to be able provide a service recovery. The authors posit that managerial action is vital to positively impacting the soundscape.

The purpose of this study is to assess how background sounds, physical sounds, and the managerial handling of situational sound problems impact customer satisfaction in a restaurant setting.

\section{Customer Satisfaction}

\section{Literature Review}

Customer satisfaction is well-established in the service literature and arguably the most important factor to measure success in a restaurant setting. For this study, customer satisfaction refers to how their perceptions of performance match with expectations based on past experience (Oliver, 1980). To summarize this theory, satisfaction is when a customer receives products or services perceived to be above expectation. On the other hand, dissatisfaction occurs if a customer receives products or services below expectation. Overall, satisfaction comes from the level of trust, delight, and commitment of customers (Hennig-Thurau et al., 2002). Importantly, several positive consequences come with satisfied customers, including a willingness to pay premium prices, positive word-of-mouth, and overall organizational performance enhancement (Mikolon et al., 2015).

Customer satisfaction regarding the different dimensions and types of restaurant sounds have been connected in previous research; for example, the level of sound occurring at a restaurant (Fikret, 2013), or the types of music restaurant-goers prefer to experience (Novak et al., 2010). Physical sounds - those caused by employee tasks such as dropping dishes onto trays, running around, moving tables and chairs, and cleaning and setting up tables - can also influence customer satisfaction (Bitner, 1992; Harrell et al., 1980). While important, most of the time, physical sounds such as heating, air conditioning and kitchen equipment can be managed in a restaurant setting (Zemke et al., 2011). Finally, several studies have shown situational sounds, those caused by other customers in the same setting, also reflect negatively on the service firm (Adams et al., 2006; Bitner, 1992; Grove \& Fisk, 1997). However, since situational sounds are not completely control by managers, a proactive service strategy, when used, can alleviate the negative impact of situational sounds. Instead of reacting after a service failure, proactive customer service positively impacts customer satisfaction by anticipating service failures and taking actions to prevent them (Jin et al., 2010; Raub \& Liao, 2012; Söderlund, 2018).

\section{Background Sounds}

Background sounds refer to audio environments like musical compositions, radio or recorded programming, and other music (Schafer, 1994). Restaurants can select a unique background music that is related to the restaurant style or theme. For instance, Chinese restaurants can play traditional Chinese music. Background music is generally used to enhance the activities and contribute positively to the service environment. However, it can overwhelm the service environment and negate the positive effect (Zemke et al., 2011). If the restaurant is not playing the right music, customers may feel that the music is unpleasant and they may not be able to fully enjoy the service. In addition, music volume can vary from soft to loud and tempo varies from slow to fast. According to Fikret (2013), customers said that music made them more relaxed during shopping, and they were willing to spend more time in the shopping mall when music is playing. Likewise, previous studies have shown that loud music caused customers to spend less time in stores and perceive the experience as unpleasant, affecting customer return intention (Fikret, 2013).

Similar to the volume, the tempo of background music also influences customers' experience. As indicated by Caldwell \& Hibbert (1999), the tempo of music played in a restaurant has an effect on the amount of time customers spend in the restaurant. According to Mattila \& Wirtz (2001), customers spent less time in a dining experience when the restaurant played fast-tempo music in the dining 
room; however, customers were willing to spend more time enjoying their meals listening to slow-tempo music.

Because restaurants can modify background sounds to suit customers, it's not surprising that previous studies (Christie, 2004; Rohrmann, 2003) have shown that most customers assessed the music played in cafes and restaurant as acceptable. However, Rohrmann (2003) indicated that the restaurant environment has changed. Louder soundscapes are acceptable or at least tolerated more compared to ten years ago. Too few results show the soundscape acceptable rate on customers' perceptions in the restaurant industry.

Hypothesis 1: Background sounds impact customer satisfaction.

\section{Physical Sounds}

Physical sounds are defined as "furniture movement, building equipment (heating/cooling, kitchen equipment, cash registers), and exterior and street noise that infiltrates the space" (Zemke et al., 2011, p. 257). Examples of physical sounds caused by employees are dropping dishes onto a bus tray, running around, moving tables and chairs, and cleaning and setting up tables. These sounds are harsh, and customers may feel uncomfortable hearing them which could affect customer satisfaction and other marketing outcomes. These short duration sounds do not cause immediate health problems; however, long-term exposure to that kind of noise can cause customers to have hearing problems (Mondal, 2014). Physical sound levels in restaurants normally should range between $60 \mathrm{dBA}$ to $80 \mathrm{dBA}$ (Christie, 2004) and Rohrmann (2003) found that many restaurants exceeded these levels.

While physical sounds can influence customer satisfaction (Bitner, 1992; Harrell et al., 1980; Rabb et al., 2011), most of the time, sounds such as heating, air conditioning and kitchen equipment can be managed or lessened by employees in a restaurant setting (Zemke et al., 2011). Instead of the employees dropping dishes, silverware, and glassware onto a bus tray, employees can adjust the level of sound by carefully laying down these items in an organized fashion in order to minimize noise levels.

Furthermore, these physical sounds may cause difficulties for employees when trying to listen to customers. It may cause them to make mistakes such as taking incorrect orders or missing special requirements during service delivery. So, indirectly, overly-loud physical sounds can affect customer satisfaction. If these physical sounds can be reduced, the customers' perceptions of service quality will be increased (Bitner, 1992; Harrell et al., 1980).

Hypothesis 2: Physical sounds impact customer satisfaction.

\section{Proactive Customer Service Regarding Situational Sounds}

In addition to sounds from the restaurant, customers' perceptions have been found to be influenced by the misbehavior of other customers (Adams et al., 2006; Grove \& Fisk, 1997; Martin, 1996). Based on Kotler et al. (2013), service inseparability means that the customers are part of the product and therefore can impact the quality of service delivery. Situational sounds address how customers are influenced by other customers dining in the same restaurant and highlight a type of sound that cannot be easily managed by employees. For example, situational sounds can be loud conversation among fellow customers or crying and fussing children. Those unpleasant situational sounds make it difficult for other customers to enjoy their experience or carry on a normal volume conversation with their co-diners (Christie, 2004). Unpleasant sounds generated by customers will affect other customers' service expectations and perceptions of the service quality (Novak et al., 2010).

Situational sounds are not easily controlled but influence customers' revisit intentions (Huang et al., 2010). Moreover, managers and employees cannot force their customers to control their voices in the restaurant, and there is no easy method to reduce unpleasant sounds generated by customers. Thus, the concern with situational sounds might not be as much about how situational sounds impact customer satisfaction, but rather the way in which managers handle situational sound problems. Therefore, proactive customer service in handling a situational sound issue is arguably key.

Shin et al. (2017) defines proactive customer service as "anticipating potentially problematic issues and acting prior to customer recognition or reaction to prevent service failure from occurring” (p. 165). Proactive customer service plays an essential role in today's environment since service failure avoidance should be as important as service recovery because not every dissatisfied customer complains, and many times managers are not even aware of the service failure to provide a service recovery. Anecdotally, 70-95\% of customers who experience a dissatisfying service encounter do not bother complaining (Worsfold et al., 2007). Additionally, Mikolon et al. (2015) stated that failure encounters are less manageable in the service industry due to external factors such as the customers themselves. Referring to the inseparability nature of the service industry, customers are part of the service delivery process and therefore, the service delivery process is not completely controlled by managers to therefore guarantee service quality (Kotler et al., 2013). In addition to practicing service recovery strategies, service providers should anticipate potential problems and take the initiative to solve problems and prevent failures before they happen. In this study, proactive customer service refers to restaurant managers proactively taking care of situational sound problems before they affect other customers. For instance, managers moving customers further away from the noise before customers voice their concerns.

Barkai \& Harison (2011) proposed a preventative service management framework to elaborate the four stages in the proactive customer service approach: "detection, prevention, notification and follow-up" (p. 21). In the detection stage, managers constantly monitor the service delivery process to prevent possible service failures from happening. In the prevention stage, managers implement necessary standard operation procedures to remove all the risk factors which might cause service failures. In the notification stage, managers provide relevant information to those likely-tobe impacted customers and explain to them about the possible service failures even though customers might not rec- 
ognize the issues. In the follow-up stage, managers can also provide detailed information to the complaining customers and offer compensation to recover the service failure where needed.

For example, a restaurant may have a scenario where the dish machine in the banquet kitchen is down and servers need to carry dishes from the banquet area through the restaurant. In a preventative service management framework, managers would detect the potential service issues (carrying additional dishware through the restaurant which could make noise), develop alternative options to prevent additional noise (change procedure to only carry dishes through the restaurant during off-peak times), notify guests in advance that there may be some additional traffic in the restaurant (servers can inform guests there may be some additional noise), and finally, consistently check in with customers during their dining experience to ensure everything is meeting expectations (offer service recovery if needed).

Practicing proactive customer service has been shown to influence customer satisfaction and repurchase behavior (Worsfold et al., 2007). Proactive customer service enhances customer satisfaction prior to the occurrence of the service failure (Mikolon et al., 2015). Compared to reacting to the service failure, customers prefer companies taking initiative to identify, expect, prevent, and solve potential service failure before they happen (Shin et al., 2017). Therefore, restaurant managers should train themselves and their employees to be proactive in terms of customer service.

Proactive customer service should be part of the organization's service culture and be considered a key element in customer satisfaction. Service extras, whether anticipated or unanticipated due to a service recovery are not necessarily salient in customers perceptions of service quality (Bitner, 1990). Rather, customers prefer to have the service firm follow through on the delivery of promised service extras in a consistent manner (Raub \& Liao, 2012).

Jin et al. (2010) proposed a proactive customer service strategy when dealing with Digital Subscriber Line (DSL) services. As in restaurants, traditional DSL service solutions are reactive in nature and initiated by the customer. They found that a proactive customer service approach to troubleshooting customer issues, reduced the number of care calls and improved customer satisfaction and resulted in greater efficiencies.

Söderlund (2018) studied employee proactivity and its impact on customer satisfaction in a retail grocery store setting. The results found that proactivity did indeed increase customer satisfaction, which was sequentially facilitated by both perceived employee effort and performance. Therefore, it is important that service organizations have a strong culture of proactive customer service and that it is supported from top to bottom. Additionally, employees need to be supported and trained to anticipate service challenges such as situational sounds and how to handle any potential issues before they impact the customer and result in a service failure.

Hypothesis 3: Proactive customer service regarding situational sound impact customer satisfaction.

Hypothesis 4: Customer satisfaction is influenced by the interactive effects of background sounds, physical sounds,

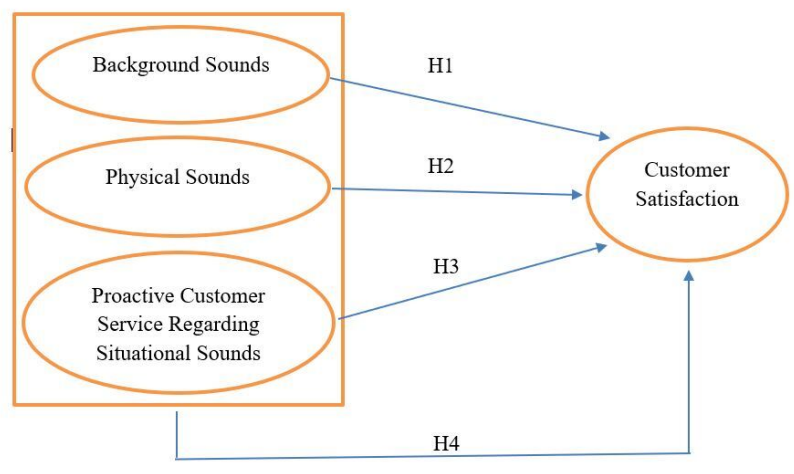

Figure 1. Proposed Model

and proactive customer service regarding situational sound.

\section{Methodology}

\section{Survey Instrument}

There are three parts to the study. First, scenarios for each of the three types of sound situations were composed. Referring to Christie's (2004) study, the authors created eight scenarios to see if customers are impacted by background sounds and physical sounds and if the managers proactively or reactively handle situational sound problems. The $2 * 2 * 2$ scenarios are: background sounds (distract vs. did not distract) * physical sounds (distract vs. didn't distract) * situational sound problem responses (proactive vs. reactive). The second part measures customer satisfaction. The following four questions were modified from Hennig-Thurau et al. (2002): Q1) My choice of this restaurant was a wise one. Q2) I am always delighted with this restaurant, Q3) Overall, I am satisfied with this restaurant, and Q4) I think I did the right thing when I decided to dine in this restaurant. The third part asks participants' demographic background, such as visiting frequency, average check and gender.

\section{Eight Scenarios}

Participants were told, "We are interested in how unpleasant sound affects customers' perceptions in the restaurant industry. Please read the following scenario carefully and imagine that the incident happened to you during a visit to a restaurant, and then answer the questions. The key to the success of this research depends on whether you are really able to imagine yourself in these situations." Each participant was assigned to one scenario. The eight different scenarios tested in this study (numbered 1-8) are detailed below.

\section{\#1 BS-Distract, PS-Distract, SS-Manager handled situational sound problem proactively}

Imagine that you dine in a restaurant where the food quality is good, service is satisfactory, and price is reasonable. Nevertheless, the music playing in this restaurant distracts you. You also find it is hard to relax because of the sounds from the kitchen and air conditioning, chair/table 
scraping, and glasses clinking. Additionally, there is a group of customers sitting close to your table who are talking/ laughing very loudly which impacts your dining experience. Consequently, the manager moves you to another table further away from the noise.

\section{\#2 BS-Distract, PS-Distract, SS-Manager handled situational sound problem reactively}

Imagine that you dine in a restaurant where the food quality is good, service is satisfactory, and price is reasonable. Nevertheless, the music playing in this restaurant distracts you. You also find it is hard to relax because of the sounds from the kitchen and air conditioning, chair/table scraping, and glasses clinking. Additionally, there is a group of customers sitting close to your table who are talking/ laughing very loudly which impacts your dining experience. Consequently, the manager does not move you to another table further away from the noise.

\section{\#3 BS-Distract, PS-Not Distract, SS-Manager handled situational sound problem proactively}

Imagine that you dine in a restaurant where the food quality is good, service is satisfactory, and price is reasonable. Nevertheless, the music playing in this restaurant distracts you. However, you find the sounds from the kitchen and air conditioning, chair/table scraping, and glasses clinking is acceptable. Additionally, there is a group of customers sitting close to your table who are talking/laughing very loudly which impacts your dining experience. Consequently, the manager moves you to another table further away from the noise.

\section{\#4 BS-Distract, PS-Not Distract, SS-Manager handled situational sound problem reactively}

Imagine that you dine in a restaurant where the food quality is good, service is satisfactory, and price is reasonable. Nevertheless, the music playing in this restaurant distracts you. However, you find the sounds from the kitchen and air conditioning, chair/table scraping, and glasses clinking is acceptable. Additionally, there is a group of customers sitting close to your table who are talking/laughing very loudly which impacts your dining experience. Consequently, the manager does not move you to another table further away from the noise.

\section{\#5 BS-Not Distract, PS-Distract, SS-Manager handled situational sound problem proactively}

Imagine that you dine in a restaurant where the food quality is good, service is satisfactory, and price is reasonable. Nevertheless, the music playing in this restaurant does not distracts you. However, you find it is hard to relax because of the sounds from the kitchen and air conditioning, chair/table scraping, and glasses clinking. Additionally, there is a group of customers sitting close to your table who are talking/laughing very loudly which impacts your dining experience. Consequently, the manager moves you to another table further away from the noise.

\section{\#6 BS-Not Distract, PS-Distract, SS-Manager handled situational sound problem reactively}

Imagine that you dine in a restaurant where the food quality is good, service is satisfactory, and price is reasonable. Nevertheless, the music playing in this restaurant does not distract you. However, you find it is hard to relax because of the sounds from the kitchen and air conditioning, chair/table scraping, and glasses clinking. Additionally, there is a group of customers sitting close to your table who are talking/laughing very loudly which impacts your dining experience. Consequently, the manager does not move you to another table further away from the noise.

\section{\#7 BS-Not Distract, PS-Not Distract, SS-Manager handled situational sound problem proactively}

Imagine that you dine in a restaurant where the food quality is good, service is satisfactory, and price is reasonable. Nevertheless, the music playing in this restaurant and the sounds from the kitchen and air conditioning, chair/ table scraping, and glasses clinking is acceptable. Additionally, there is a group of customers sitting close to your table who are talking/laughing very loudly which impacts your dining experience. Consequently, the manager moves you to another table further away from the noise.

\section{\#8 BS-Not Distract, PS-Not Distract, SS-Manager handled situational sound problem reactively}

Imagine that you dine in a restaurant where the food quality is good, service is satisfactory, and price is reasonable. Nevertheless, the music playing in this restaurant and the sounds from the kitchen and air conditioning, chair/ table scraping, and glasses clinking is acceptable. Additionally, there is a group of customers sitting close to your table who are talking/laughing very loudly which impacts your dining experience. Consequently, the manager does not move you to another table further away from the noise.

\section{Data Collection and Respondent Profile}

A non-probability convenience sampling method was used for this study. The data was collected from a Chinese \& Japanese Restaurant in a metropolitan city in the northeastern area of the USA. The reason we selected this particular restaurant is that according to the Restaurant, Food and Beverage Market Research Handbook 2018-2019, the most popular restaurant type in the USA is local casual-dining. Fifty-seven percent of the participants indicated that local casual-dining restaurants are the type of restaurants they visit in a typical month and the participating restaurant belongs to this category (Miller \& Washington, 2018).

The surveys were distributed by one of the authors to customers who dined in the restaurant during lunch time (12:00pm-2:00pm) and dinner time (6:00pm-8:00pm). The survey questionnaires were printed in eight different colors, one color for each scenario. Participants were randomly assigned to a scenario. For example, based on the order of seating, once diners were settled at their tables, the author approached the first diner to ask for their participation in this study with a scenario one questionnaire, then, the au- 
thor approached the second diner with a scenario two survey questionnaire, etc. As indicated in Cohen et al. (2007), "experimental methodologies required a sample size of no fewer than fifteen cases” (p. 102). A total of eight scenarios each with fifteen participants yielded a total of 120 participants in this study. The data collection lasted for three weeks. One hundred fifty customers were approached for this study, 140 surveys were returned and among those, 120 were valid, generating a response rate of $80 \%(120 / 150)$.

The participants were mostly female $(51.7 \%)$. Furthermore, $24.2 \%$ of the respondents were single; $69.2 \%$ were married or in a domestic partnership; $0.8 \%$ of the respondents were widowed; $4.2 \%$ of the respondents were divorced, and $2 \%$ of the respondents were separated. When respondents were asked about the highest education level completed, they replied $25.8 \%$ high school; $52.5 \%$ college/ university; and $21.7 \%$ master's degree or higher. Furthermore, $5 \%$ of the participants are Asian; 0.8\% African American; 90.8\% Caucasian /White; $0.8 \%$ Latino; $2.5 \%$ of participants identified as other. In addition, participants when asked about how often do you visit a casual restaurant per month, $10.8 \%$ of participants answered that they eat out two or less times per month, $41.7 \%$ of answered three to five times per month, $30.8 \%$ of answered six to eight time per month, $16.7 \%$ answered over eight times per month. When participants were asked about their average dining budget per month in a casual restaurant, $19.2 \%$ answered spent $\$ 100$ or less, $31.7 \%$ answered $\$ 101$ to $\$ 200,25 \%$ answered $\$ 201$ to $\$ 300,12.5 \%$ answered $\$ 301$ to $\$ 400,9.2 \%$ answered $\$ 401$ to $\$ 500$, and $2.5 \%$ answered more than $\$ 501$.

\section{Hypothesis Testing Results and Discussion}

Four independent variables were investigated in a $2 \mathrm{x} 2 \mathrm{x}$ 2 design and therefore, a Three-Way MANOVA analysis was used to examine the four hypotheses (Moore et al., 1994). The results of this study confirmed that background sounds (H1), physical sounds (H2), and managers' proactive customer service regarding situational sounds (H3) impact customer satisfaction. However, the interactive effects of background sounds, physical sounds, and managers' proactive customer service regarding situational sounds (H4) do not influence customer satisfaction.

H1 was supported. The results indicate that background sounds influence customer satisfaction in two aspects: Q2-I am always delighted with this restaurant $(\mathrm{F}=4.201$; $\rho=0.043$ ) and Q4- whether they believe they made the right decision to dine in this restaurant $(\mathrm{F}=5.292 ; \rho=0.023)$.

Caldwell \& Hibbert (1999) found that background sounds influence customer satisfaction. Background music can also influence the customer's experience and affects the amount of time they spend in a restaurant. In this study, background sounds impacted whether customers were delighted with the restaurant and if customers thought they made the right decision to dine in this restaurant; even though background sounds did not impact if customers thought their choice of the restaurant was a wise one and if the customer was satisfied with the restaurant. Based on the authors' work experience, many times when customers are satisfied with food and service quality at that moment; they may think background sounds such as tempo and volume is not that impor- tant during the dining time.

H2 was supported. The results indicate that physical sound impacts participants' satisfaction in one aspect: whether they believe they made the right decision to dine in the restaurant $(\mathrm{F}=5.292 ; \rho=0.023)$. Physical sounds can influence customer satisfaction, such as sounds generated by heating, air conditioning and kitchen equipment (Bitner, 1990; Harrell et al., 1980). A possible explanation for this result may be customers understand that physical sounds (heating, air condition and kitchen equipment) are difficult to reduce since they are necessary for the restaurant to operate and the sound may not be too annoying while dining. Also, customers may consider food quality and service quality to be of more importance compared to physical sounds.

$\mathrm{H} 3$ was supported. The results indicate that how managers handle the problems caused by situational sounds influence customers satisfaction in all four aspects: Q1. My choice of this restaurant was a wise one ( $\mathrm{F}=9.846$; $\rho=0.002)$, Q2. I am always delighted with this restaurant $(\mathrm{F}=5.061 ; \rho=0.026), \mathrm{Q} 3$. Overall, I am satisfied with this restaurant $(\mathrm{F}=4.770 ; \rho=0.031)$, and $\mathrm{Q} 4$. I think I did the right thing when I decided to dine in this restaurant $(\mathrm{F}=6.252 ; \rho=0.014)$. The results were consistent with previous studies. How managers handled the problem caused by situational sounds significantly impacted several issues: such as the customer choice of the restaurant was a wise one, customers are always delighted with the restaurant, and customers thought they made the right decision to dine in the restaurant. The possible explanation for this result is that situational sounds may be annoying and very sensitive for the customers. Situational sounds are difficult to control by managers and hard to resolve. Even though situation sounds are not generated by the restaurant, they still affect customer revisit intention.

H4 was not supported. The interactive effects of background sounds (distracts vs. did not distract) * physical sounds (distracts vs. didn't distract) * situational sound problems (reactive .vs. proactive) do not significantly influence any aspects in customer satisfaction with $\alpha=.05$ level.

\section{Theoretical Implications}

The results of this study confirm the first three hypotheses where background sounds, physical sounds, and proactive customer service influence customer satisfaction. The results are consistent with previous studies and extends the work of authors such as Wilson (2003) regarding background sounds and Zemke et al. (2011) regarding physical sounds. Additionally, the results indicate that how managers handle problems caused by situational sounds influence customer satisfaction. The results are in line with research by Andaleeb \& Conway (2006) who found that customer satisfaction was influenced most by responsiveness of frontline employees. In particular, the results show that this area has the greatest impact on customer satisfaction in a restaurant setting.

Recognizing the importance of how ambient sounds influence customer satisfaction, previous studies only evaluated how background sounds, physical sounds, and situational sounds influence customer satisfaction (Bitner, 1992; 
Table 1. Comparison of Means (Three-Way MANOVA) for Customer Satisfaction

\begin{tabular}{|c|c|c|c|c|}
\hline Question & df & $\mathrm{F}$ & $\mathrm{p}$ & Mean \\
\hline \multicolumn{5}{|c|}{ Background Sounds } \\
\hline Q1) My choice of this restaurant was a wise one & 1 & 2.613 & .109 & $\begin{array}{l}\text { Distract }=4.967 \\
\text { Not Distract }=5.533\end{array}$ \\
\hline Q2) I am always delighted with this restaurant & 1 & 4.201 & $.043^{*}$ & $\begin{array}{l}\text { Distract }=4.950 \\
\text { Not Distract }=5.633\end{array}$ \\
\hline Q3) Overall, I am satisfied with this restaurant & 1 & 3.558 & .062 & $\begin{array}{l}\text { Distract }=5.233 \\
\text { Not Distract }=5.867\end{array}$ \\
\hline Q4) I think I did the right thing when I decided to dine in this restaurant & 1 & 5.292 & $.023^{*}$ & $\begin{array}{l}\text { Distract }=5.133 \\
\text { Not Distract }=5.900\end{array}$ \\
\hline \multicolumn{5}{|c|}{ Physical Sounds } \\
\hline Q1) My choice of this restaurant was a wise one & 1 & 3.264 & .074 & $\begin{array}{l}\text { Distract }=4.933 \\
\text { Not Distract }=5.567\end{array}$ \\
\hline Q2) I am always delighted with this restaurant & 1 & 3.801 & .054 & $\begin{array}{l}\text { Distract }=4.967 \\
\text { Not Distract }=5.617\end{array}$ \\
\hline Q3) Overall, I am satisfied with this restaurant & 1 & 2.848 & .094 & $\begin{array}{l}\text { Distract }=5.267 \\
\text { Not Distract }=5.833\end{array}$ \\
\hline Q4) I think I did the right thing when I decided to dine in this restaurant & 1 & 5.292 & $.023^{*}$ & $\begin{array}{l}\text { Distract }=5.133 \\
\text { Not Distract }=5.900\end{array}$ \\
\hline \multicolumn{5}{|c|}{ Proactive Service } \\
\hline & df & $\mathrm{F}$ & $\mathrm{p}$ & Mean \\
\hline Q1) My choice of this restaurant was a wise one & 1 & 9.846 & $.002^{* *}$ & $\begin{array}{l}\text { Reactive }=4.700 \\
\text { Proactive }=5.800\end{array}$ \\
\hline Q2) I am always delighted with this restaurant & 1 & 5.061 & $.026^{*}$ & $\begin{array}{l}\text { Reactive }=4.917 \\
\text { Proactive }=5.667\end{array}$ \\
\hline Q3) Overall, I am satisfied with this restaurant & 1 & 4.770 & $.031^{*}$ & $\begin{array}{l}\text { Reactive }=5.183 \\
\text { Proactive }=5.917\end{array}$ \\
\hline Q4) I think I did the right thing when I decided to dine in this restaurant & 1 & 6.252 & $.014^{*}$ & $\begin{array}{l}\text { Reactive }=5.100 \\
\text { Proactive }=5.933\end{array}$ \\
\hline \multicolumn{5}{|c|}{ Background Sounds x Physical Sounds $x$ Proactive Service } \\
\hline & $\mathrm{df}$ & $\mathrm{F}$ & $\mathrm{p}$ & \\
\hline Q1-My choice of this restaurant was a wise one & 1 & .443 & .507 & \\
\hline Q2) I am always delighted with this restaurant & 1 & .442 & .517 & \\
\hline Q3) Overall, I am satisfied with this restaurant & 1 & .158 & .692 & \\
\hline Q4) I think I did the right thing when I decided to dine in this restaurant & 1 & .090 & .765 & \\
\hline
\end{tabular}

$* \mathrm{P}<0.05$ and ${ }^{* * *} \mathrm{P}<0.01$

Christie, 2004; Huang et al., 2010; Zemke et al., 2011). Furthermore, scholars have also investigated the relationship between proactive service strategies and customer reactions and satisfaction (Barkai \& Harison, 2011; Mikolon et al., 2015; Shin et al., 2017). In addition to confirming the results from previous studies, the theoretical contribution of this study is integrating the concepts of soundscape and proactive service in the same theoretical framework.

Moreover, based on the author's years of work and consulting experience with small independent restaurants owners/chefs, it is not realistic to completely control situational sounds and most importantly, industry practice is not to focus on controlling situational sounds, but rather to manage situation sounds through proactive service strategies. In order to better connect the academic theories with industry current practices, this study combines these two streams of theories into one theoretical framework. Different from previous studies which merely assessed how back- ground sounds, physical sounds, and situational sounds impact customer satisfaction, this study retained the background sounds and physical sounds in the theoretical framework since restaurant managers can control these two sounds and instead of simply evaluating how situational sounds impact customer satisfaction, this study evaluated the impact of how managers handle situational sounds and the influence on customer satisfaction.

As indicated by Schuckert \& Law (2015), when a research field is inherently practical and applied in nature, "the lack of a practical application may in turn have diminished enthusiasm for academic research" (p. 613). Restaurant businesses certainly belong to the practical and applied knowledge field and this modified theoretical framework better links the academic theoretical concepts with current industry practices and encourages further scholarly research in this field.

Furthermore, the concept of the service recovery paradox 
(SRP) has been an important research area in service marketing research (El-Manstrly et al., 2016). Some scholars support a notion that a successful service recovery action fixes service failures and can actually enhance customer satisfaction (Kaur \& Singh, 2020), whereas other scholars claim that providers should strive to deliver services successfully the first time because a superior service recovery is "highly contingent upon the context and situation" (Hazarika \& Dhaliwal, 2019, p. 30). It is important to remember, dissatisfied customers may not always give service providers a second chance to make things right. Based on the results of this study, when managers handle situational sounds proactively, customers' levels of satisfaction are significantly higher than when managers employ a reactive strategy and therefore support the notion of doing things right the first time.

\section{Managerial Implications}

The results of this study reveal important insights for restaurant managers. Importantly, the results were consistent with previous studies (Caldwell \& Hibbert, 1999; Mikolon et al., 2015; Shin et al., 2017), but also extended understanding. By controlling for and comparing different sound situations, the authors' found that the way managers handled situational sound problems has the greatest impact and physical sounds have the least impact on customer satisfaction. Many of the participants, considered noises from heating and cooling system part of normal restaurant operations reasonable and therefore, those sounds were not bothersome. More importantly, customers pay attention to and care about the quality of service delivered. It is well received by customers when managers take the initiative and act proactively to enhance customer experiences. While uncomfortable sounds are going to occur, what managers do about it is crucial to customer satisfaction.

The results indicate that background sounds influence customer satisfaction and extends the work of authors such as Wilson (2003). Important to managers, background sounds can be managed by restaurant staff to avoid negative outcomes and amplify the likelihood of positive customer outcomes. Background noises refer to musical compositions, radio programs, and acoustic music (Schafer, 1994). It is a major factor of the soundscape in the restaurant and could impact customer satisfaction. Background sounds can be adjusted easily in restaurant settings and managers can select different kinds of background music based on the type of restaurant. For example, if there is an important sporting event occurring such as the Super Bowl, customers may want the TVs on and at higher volume as they want to watch the game and it a part of the overall dining experience. Conversely, a couple out on a date in a fine-dining restaurant may want soothing music at a slow tempo and low volume to complement their dining experience. Thus, restaurant managers should select the appropriate background music volume and tempo which best fits their restaurant setting and customer preferences.

The results indicate that the physical sounds also influence customer satisfaction. Similar to background sounds, physical sounds can be managed. Customers may think these sounds are an annoyance, but customers may em- pathize to a degree that the sounds coming from equipment are difficult to completely avoid. For examples, diners in a restaurant in a large city with close surroundings expect that there may be exterior noise from the street such as sirens and car horns.

Additionally, restaurant design might help. Today’s systems such as heating and air conditioning are designed to run more efficiently and quietly. Designers can place glass between the dining room and open kitchens to minimize kitchen noises for customers. Furthermore, designers can add decorative sound absorbing panels in strategic places that complement the design and help absorb physical sounds. Finally, managers should train employees how to properly set up and bus tables and transport tableware to minimize physical sounds.

The results also indicate that how managers handle the problems caused by situational sounds influence customer satisfaction. In particular, the results showed that this area has the greatest impact on customer satisfaction in a restaurant setting. For example, it impacted whether the customer considered their restaurant choice to be wise, the customer's delight with the restaurant, the customer's overall satisfaction with the restaurant, and whether the customer believed they did the right thing when deciding to dine in the restaurant.

How managers handle the problems caused by the situational sounds is exemplified in the following example. A customer, "customer one" comes into a restaurant with his fiancé to have dinner and hear the featured guitarist/vocalist for the evening. Shortly after, a large group of approximately 25 individuals enter the restaurant and are seated directly next to customer one. The restaurant has several smaller rooms as well as the main room. The large party is celebrating a marriage engagement. As the night progresses, the situational sounds from the large group increase. Customer one and his fiancée cannot not hear the musician or even have a conversation. Their service experience is rapidly declining. At one point in the night, the host of the large group starts whistling loudly and making a lot of noise. Customer one asks the host of the large group to stop, but nothing happens. Expletives and words are exchange between the two guests. Upon returning from the restroom, three individuals from the large group yell at customer one and block him from returning back to his table. After a heated exchange of words, a physical altercation occurs and customer one sustains several injuries.

This scenario illustrates the importance of managers handling problems caused by situational sounds. A proactive customer service approach could have delivered a different outcome and led to customer satisfaction in previous scenario. Management should have detected that a large party is prone to creating additional situational sounds and came up with other seating arrangements. Managers should have been monitoring the situation to prevent the outcome that occurred. Since the restaurant has private rooms, the large group should have been seated away from other guests. Managers could have also told customer one that the large group was given a private room to isolate the loud noises. By anticipating potential service issues, service failures can be avoided. Finally, even if the large group was moved away after the first altercation, the restaurant could 
have offered the large group a complimentary cake to celebrate the engagement. Managers could have also offered complimentary food to customer one for his inconvenience.

Managers should also develop and train employees to practice proactive customer service by developing (1) selfinitiated behaviors where employees demonstrate performance that goes above and beyond implicit expectations, (2) long-term oriented thinking processes where employees can exercise forward-thinking abilities to anticipate customer needs before customers even ask, and (3) persistent service behavior where employees need to follow through whatever the restaurant promises customers (Rank et al., 2007).

Proactive customer service plays a crucial role in creating memorable and outstanding customer experiences which can lead to customer satisfaction. In the past, the focus in service organizations centered on effective service recovery models (a reactive approach). Today, that focus is shifting to creating service models that anticipate customer issues by developing preventative service protocols and procedures (a proactive approach). In a restaurant setting, the focus is on quality food and attentive service to customers; all things that are in the control of restaurant management. However, when service failures occur due to situations that may be beyond the control of the restaurant, managers typically deal with these scenarios reactively with a service recovery. Furthermore, since not all dissatisfied customers complain, managers may not even have the opportunity to provide a service recovery, which could result in customers leaving dissatisfied never to return to the service organization.

\section{Limitations and Recommendations for Future Research}

While great care was exerted, there are limitations to the current study. Based on the investigation of the influence of different types of noises and management's proactive service strategies on customer satisfaction, this study utilized a convenience sampling method. However, the limitation of a convenience sampling is that the results from this study can't be generalized to the population as a whole. Therefore, utilizing the results of this study for broader application should be done so with caution. In addition, the second limitation is that the survey was distributed only in the USA. If replicated, findings from other countries might be dissimilar due to the differences in cultures. Furthermore, the evaluation of the participants' satisfaction was done with hypothetical rather than actual scenarios regarding soundscape. While this helps control for greater analysis of the independent variables, the study should be replicated to established field validity. There is regularly a trade-off between internal and external validity. Future research might find results to be more accurate with actual scenarios since one of the five senses is hearing, which might be hard for study participants to imagine the sound level based on simply reading the scenario. Finally, this study placed more focus on participants' restaurant perceptions and visiting behaviors and failed to gather information about the participants' age, thus future research should add more demographic questions to better understand the participants in the study. 


\section{REFERENCES}

Adams, M., Cox, T., Moore, G., Croxford, B., Refaee, M., \& Sharples, S. (2006). Sustainable Soundscapes: Noise Policy and the Urban Experience. Urban Studies, 43(13), 2385-2398. https://doi.org/10.1080/00420980 $\underline{600972504}$

Andaleeb, S. S., \& Conway, C. (2006). “Customer Satisfaction in the Restaurant Industry: An Examination of the Transaction - Specific Model.” Journal of Services Marketing, 20(1), 3-11. https://do i.org/10.1108/08876040610646536

Barkai, O., \& Harison, E. (2011). Preventive Service Management: Towards Pro-Active Improvement Of Service Quality. Review of Business Information Systems (RBIS), 15(4), 19-30. https://doi.org/10.1903 0/rbis.v15i4.6009

Belluz, J. (2018). Why Restaurants Became So Loud - And How To Fight Back. http://www.vox.com/2018/4/18

Bitner, M. J. (1990). Evaluating Service Encounters: The Effects of Physical Surroundings and Employee Responses. Journal of Marketing, 54(2), 1-18. https://d oi.org/10.2307/1251871

Bitner, M. J. (1992). Servicescapes: The Impact of Physical Surroundings on Customers and Employees. Journal of Marketing, 56(2), 57-71. https://doi.org/1 $\underline{0.2307 / 1252042}$

Bramley, E. (2019). Great Food, But Please do Something About the Noise' - the Battle for Quieter Restaurants. ht tps://www.theguardian.com/food/25019/may/09

Caldwell, C., \& Hibbert, S. A. (1999). Play That One Again: The Effect of Music Tempo on Consumer Behavior in a Restaurant. European Advances in Consumer Research, 4, 58-62.

Christie, L. H. (2004). Psycho - to - Building Acoustics: Are Bars, Cafe's and Restaurants Acceptable Acoustic Environments? http://www.victoria.ac.nz/architectur e/centres/cbpr/publications/acoustics-in-the-field/pd fs/1-christie-report.pdf

Clark, J. (2014). What's Your Biggest Complaint About Restaurants? USATODAY. https://www.usatoday.com/ story/dispatches/2013/12/03/2014-zagat-best-restaur ants/3807051/

Cohen, L., Manion, L., \& Morrison, K. (2007). Research methods in education. Routledge. https://doi.org/10.43 24/9780203029053

El-Manstrly, D., Liu, G., \& Rosenbaum, M. (2016). An Empirical Examination of the Interrelationships Between Service Recovery Paradox and Its Key Antecedents and Outcomes. In M. Groza \& C. Ragland (Eds.), Marketing Challenges in a Turbulent Business Environment. Developments in Marketing Science: Proceedings of the Academy of Marketing Science (pp. 978-973). Springer International Publishing. https://doi.org/10.1007/978-3-319-1942 $\underline{8-8} 64$
Fikret, A. (2013). The Influence of Music Tempo and Occupancy Rate on Alcohol Consumption Time Spent and Money Spent in Restaurant [Master's Thesis]. htt p://essay.utwente.nl/64209/1/Akin_Fikret -s 113872 3 scriptie.pdf

Grove, S. J., \& Fisk, R. P. (1997). The Impact of Other Customers on Service Experiences: A Critical Incident Examination of "Getting Along." Journal of Retailing, 73(1), 63-85. https://doi.org/10.1016/s0022-4359(9 7) $90015-4$

Harrell, G. D., Hutt, M. D., \& Anderson, J. C. (1980). Path Analysis of Buyer Behavior Under Conditions of Crowding. Journal of Marketing Research, 17(1), 45-51. https://doi.org/10.2307/3151115

Hazarika, D. D., \& Dhaliwal, A. (2019). Service Recovery Paradox: Influence of service encounter and context. International Journal of Innovative Science and Research Technology, 4(2), 28-36.

Hennig-Thurau, T., Gwinner, K. P., \& Gremler, D. D. (2002). Understanding Relationship Marketing Outcomes. Journal of Service Research, 4(3), 230-247. https://doi.org/10.1177/1094670502004003006

Hodgson, M., Steininger, G., \& Razavi, Z. (2007). Measurement and Prediction of Speech and Noise Levels and the Lombard Effect in Eating Establishments. The Journal of the Acoustical Society of America, 121(4), 2023-2033. https://doi.org/10.1121/ 1.253557

Hsu, T. (2012). Noisy Restaurants: Taking the Din Out of Dinner. Los Angeles Times. http://articles.latimes.co m/2012/jun/08/business/la-fi-restaurant-noise-20120 $\underline{504}$

Huang, W.-H., Lin, Y.-C., \& Wen, Y.-C. (2010). Attributions and Outcomes of Customer Misbehavior. Journal of Business and Psychology, 25(1), 151-161. htt ps://doi.org/10.1007/s10869-009-9137-X

Jin, Y., Duffield, N., Gerber, A., Haffner, P., Sen, S., \& Zhang, Z.-L. (2010, November). NEVERMIND, the problem is already fixed: Proactively detecting and troubleshooting customer DSL problems [Paper presentation]. ACM Co-NEXT'10: Proceedings of the 6th International Conference, Philadelphia, PA, United States. https://doi.org/10.1145/1921168.1921178

Kaur, A., \& Singh, R. (2020). Service recovery paradox: A study of after sale services in tractor market. Journal of Xi'an University of Architecture \& Technology, 12(3), 5182-5207.

Kivela, J., Inbakaran, R., \& Reece, J. (1999). Consumer Research in the Restaurant Environment, Part 1: A Conceptual Model of Dining Satisfaction and Return Patronage. International Journal of Contemporary Hospitality Management, 11(5), 205-222. https://doi.o $\mathrm{rg} / 10.1108 / 09596119910272739$

Kotler, P. T., Bowen, J. T., \& Makens, J. (2013). Marketing for Hospitality and Tourism (6th ed.). Prentice Hall. 
Martin, C. L. (1996). Consumer-to-Consumer Relationships: Satisfaction with Other Consumers' Public Behavior. Journal of Consumer Affairs, 30(1), 146-166. https://doi.org/10.1111/j.1745-6606.1996.tb 00729.x

Mattila, A. S., \& Wirtz, J. (2001). Congruency of Scent and Music as a Driver of In-Store Evaluations and Behavior. Journal of Retailing, 77(2), 273-289. http s://doi.org/10.1016/s0022-4359(01)00042-2

Mikolon, S., Quaiser, B., \& Wieseke, J. (2015). Don’t Try Harder: Using Customer Inoculation to Build Resistance Against Service Failures. Journal of the Academy of Marketing Science, 43(4), 512-527. http s://doi.org/10.1007/s11747-014-0398-1

Mondal, P. (2014, February 27). Noise Pollution: Definition, Sources and Effects of Noise Pollution. htt p://www.yourarticlelibrary.com/speech/noise-pollutio n-definition-sources-and-effects-of-noise-pollution/ $\underline{28295 /}$

Moore, C. H., Wuensch, K. L., Hedges, R. M., \& Castellow, W. A. (1994). The effects of physical attractiveness and social desirability on judgments regarding a sexual harassment case. Journal of Social Behavior and Personality, 9, 715-730.

Morgan, J. (2016). Music to their Ears: How Sound effects Your Restaurant's Dining Experience. https://www.food abletv.com/blog/2016/7/5

National Institute on Deafness and Other Communication Disorders. (2016). Noise Levels in Restaurants-Tips for Protecting Your Hearing. https://w ww.noisyplanet.nidcd.nih.gov/have-you-heard/noiselevels-restaurants

Novak, C. C., La Lopa, J., \& Novak, R. E. (2010). Effects of Sound Pressure Levels and Sensitivity to Noise on Mood and Behavioral Intent in a Controlled Fine Dining Restaurant Environment. Journal of Culinary Science \& Technology, 8(4), 191-218. https://doi.org/1 $\underline{0.1080 / 15428052.2010 .535756}$

Oliver, R. L. (1980). A Cognitive Model of the Antecedents and Consequences of Satisfaction Decisions. Journal of Marketing Research, 17(4), 460-469. https://doi.org/10.2307/3150499

Rabb, C., Zemke, D. V., Hertzman, J. L., \& Singh, D. (2011). Restaurants Customers' Perceptions of Noise and Their Satisfaction and Loyalty Behaviors. https://w ww.tandfonline.com/doi/abs/10.1080

Rank, J., Carsten, J., Unger, J., \& Spector, P. (2007). Proactive Customer Service Performance: Relationships with Individual, Task, and Leadership Variables. Human Performance, 20(4), 363-390.
Raub, S., \& Liao, H. (2012). Doing the right thing without being told: Joint effects of initiative climate and general self-efficacy on employee proactive customer service performance. Journal of Applied Psychology, 97(3), 651-667. https://doi.org/10.1037/a0 $\underline{026736}$

Rohrmann, B. (2003). Soundscapes in Restaurants. Proceedings of the International Symposium of Acoustic Ecology, 1-9.

Schafer, R. M. (1994). Sonic Environment and the Soundscape: The Tuning of the World. Destiny Books.

Schuckert, M., \& Law, R. (2015). Hospitality and Tourism Online Reviews: Recent Trends and Future Directions. Journal of Travel \& Tourism Marketing, 32(5), 608-621.

Shin, H., Ellinger, A. E., Mothersbaugh, D. L., \& Reynolds, K. E. (2017). Employing Proactive Interaction for Service Failure Prevention to Improve Customer Service Experiences. Journal of Service Theory and Practice, 27(1), 164-186. https://doi.org/1 0.1108/jstp-07-2015-0161

Söderlund, M. (2018). The proactive employee on the floor of the store and the impact on customer satisfaction. Journal of Retailing and Consumer Services, 43, 46-53. https://doi.org/10.1016/i.jretcons er.2018.02.009

Spence, C. (2014). Noise and Its Impact on the Perception of Food and Drink. Flavour, 3(1). https://do i.org/10.1186/2044-7248-3-9

Turley, L. W., \& Milliman, R. E. (2000). Atmospheric Effects on Shopping Behavior. Journal of Business Research, 49(2), 193-211. https://doi.org/10.1016/s01 48-2963(99)00010-7

Wells, P. (2020). Is Restaurant Noise a Crime? Our Critic Mounts a Ringing Defense. https://www.nytimes.com/ 2020/01/21/dining/restaurant-noise-level-loud.html

Wilson, S. (2003). The Effect of Music on Perceived Atmosphere and Purchase Intentions in a Restaurant. Society and Psychology Research, 31(1), 93-112. http s://doi.org/10.1177/0305735603031001327

Worsfold, K., Worsfold, J., \& Bradley, G. (2007). Interactive Effects of Proactive and Reactive Service Recovery Strategies: The Case of Rapport and Compensation. Journal of Applied Social Psychology, 37(11), 2496-2517. https://doi.org/10.1111/j.1559-18 16.2007.00267.x

Zemke, D. M., Hertzman, J. L., Raab, C., \& Singh, D. (2011). A Little More Noise and a Little Less Conversation? Ambient Noise in Restaurants. Journal of Foodservice Business Research, 14(3), 256-271. http s://doi.org/10.1080/15378020.2011.594384 